\title{
Pengembangan Metode CST (Communicative Swimming Training) Untuk Mengatasi Phobia Air Pada Anak Usia Dini
}

\author{
Rizqi Suryawati Centrum $^{a *}$, Anung Priambodo ${ }^{b}$, Agus Hariyanto ${ }^{c}$ \\ ${ }^{a}$ Pendidikan Olahraga, Pascasarjana, Universitas Negeri Surabaya, Surabaya, 60213, Indonesia \\ ${ }^{b}$ Jurusan Pendidikan Olahraga, Universitas Negeri Surabaya, Surabaya, 60213, Indonesia \\ ${ }^{c} J u r u s a n$ Kepelatihan Olahraga, Universitas Negeri Surabaya, Surabaya, 60213, Indonesia
}

Corresponding author: rizqicentrum16070805007@mhs.unesa.ac.id

\section{A R T I CLE INFO}

Article history:

Received 02 February 2019

Received in revised form 04

April 2019

Accepted 28 April 2019

Keywords:

Communicative, Swimming,

Water phobia, Early age

\begin{abstract}
A B S T R A C T
This study aims to develop a common communication between swimming trainers and students then poured into a method or procedure that can be used to overcome water phobia in early childhood, namely CST (communicative Swimming Training) method. CST method has 11 steps that can be followed to overcome water phobia in early childhood. This method is given in a communicative manner in the form of seduction, using good words, firm and accompanied by basic swimming techniques to be used in children who experience water phobias. The effectiveness of this method is evidenced by the decrease in the percentage of the amount of data in the subject I decreased by $39 \%$ and on the subject II there was a decrease of $42 \%$ taken from the difference between the data before and after the trial. It proves that this method can reduce water phobia experience in early childhood and more effective at an early age because emotional in early childhood can still be regulated than the age of preadolescence or about 9 years and above. The need for repetition of treatment that researchers provide to accelerate the healing of water phobias experienced by the child and do not forget to always pay attention to the health conditions of children who experience water phobia.
\end{abstract}

\section{Pendahuluan}

Usia dini merupakan tahap yang paling penting dalam mengenalkan olahraga dengan cara bermain tetapi juga tidak melupakan unsur dari olahraga itu sendiri yaitu berjalan, berlari dan melompat. Saat ini cabang olahraga renang merupakan cabang olahraga yang banyak diminati oleh anak usia dini, dikarenakan banyak orang tua yang mulai sadar akan manfaat renang salah satunya untuk menghindari kecelakaan saat bermain dikolam renang. Menurut Okicic, dkk (Jorgic,dkk, 2011) menyatakan "berenang ditandai dengan gerakan yang sangat sederhana yang berbeda dalam bentuk dan cara penampilannya dan berulang kali diulang pada tehnik berenang tertentu". Hal ini diperkuat oleh Farokie, dkk (2016) bahwa beragam manfaat saat melakukan olahraga renang, antara lain sebagai sarana rekreasi, sebagai aktivitas untuk terapi atau kesehatan, sebagai aktivitas pembelajaran dan sebagai olahraga yang bersifat kompetitif. Sedangkan menurut Aleksandrovil, dkk (2010) "berenang adalah salah satu kegiatan yang bisa dilakukan orang dengan jenis diagnosa orang seperti ini (neuromuscular impairments)" yang dimaksud adalah ganggun kesehatan tubuh saat tidur karena masalah pernapasan.

Orangtua yang mengikutsertakan anaknya untuk les berenang memiliki berbagai macam tujuan diantaranya agar bisa tinggi, untuk sekedar bisa, untuk jadi atlit, untuk terapi dan lain sebagainya. Tetapi dibalik tujuan tersebut ada faktor yang sangat dirahasiakan orang tua kepada pelatih yaitu salah satunya tentang terjadinya hal yang tidak dinginkan. Sebagai contoh anaknya pernah mengalami suatu kecelakan saat bermain di air atau kolam sehingga mengakibatkan trauma atau phobia air yang sangat mendalam. 
Memberikan perlakuan dalam penyembuhan ketakutan, kecemasan atau phobia air pada anak usia dini merupakan hal yang sangat sensitif. Faktor lingkungan juga memiliki pengaruh yang besar terhadap pertumbuhan psikis seorang anak yang mengalami phobia air.

Dalam masa perkembangannya menuju remaja anak tersebut akan terus melakukan hal seperti itu. Sikap yang seperti ini sangat susah di hilangkan karena dalam pembelajaran renangnya anak tersebut sangat sulit untuk dilatih pernapasan di dalam air. Pembiasaan yang seperti ini sangat patut untuk diperhatikan. Pengenalan dunia air dalam masa anak-anak sangat perlu ditingkatkan untuk menjauhkan anak-anak dari ketakutan yang dalam akan air.

Salah satu metode yang dapat digunakan untuk penyembuhan phobia tersebut adalah CST (Communicative Swimming Training). Metode CST ini adalah suatu metode pelatihan renang yang melibatkan peranan orang tua dalam kegiatan pembelajarannya. Dengan metode ini peneliti bertujuan ingin mengetahui secara khusus faktor apa saja yang mempengaruhi anak sehingga ketakutannya dengan air sangat besar dan peran orangtua dalam penanganan anak yang mengalami phobia air.

\section{Metodologi Penelitian}

Jenis penelitian yang digunakan ialah metode penelitian dan pengembangan (research \& development). Dalam bidang pendidikan Sugiyono (2015, p:9) menyatakan bahwa penelitian dan pengembangan (research \& development) merupakan metode penelitian yang digunakan untuk mengembangkan atau memvaliditasi produk-produk yang digunakan dalam pendidikan dan pembelajaran.

Penelitian pengembangan dibagi menjadi 3 bagian yang nantinya mampu menghasilkan suatu produk baru berupa metode pelatihan yaitu; 1)Tahap pra pengembangan; 2) Tahap pengembangan; 3) Desiminasi.

Langkah-langkah pembelajaran metode CST yang bisa diterapkan dalam menangani phobia air; 1) Sebelum memasuki kolam renang orang tua membiasakan anaknya untuk membasahi tubuhnya dengan air dari atas kepala (usahakan tanpa menutupi wajah si anak). 2) Ajak anak untuk memasuki kolam renang dengan cara duduk ditepi kolam dengan posisi telapak kaki masuk kedalam air usahakan di tempat yang paling dangkal (kolam tidak terlalu dalam untuk pertama kali) buat anak merasa senang dan melupakan ketakutannya. 3) Selalu ajak anak berbicara meskipun dalam keadaan anak tersebut di luar kendali jangan pernah mengeluarkan katakata memaki anak. 4) Setelah langkah 2 dan 3 mampu dilakukan dengan baik langkah selanjutnya adalah ajak si anak berjalan di kolam yang dangkal. Pelatih bisa mengajak anak berjalan dengan memegang salah satu tangan anak kemudian suruh si anak untuk berjalan menuju orang tuanya. Lakukan sampai anak mampu berjalan sendiri dan nyaman berada di kolam dangkal. Sebagai contoh pelatih bisa menyuruh si anak untuk mengambilkan pelampung atau mainan yang ada di kolam dangkal yang letaknya sedikit jauh dari si anak untuk diberikan kepada orang tuanya (selalu awasi si anak). 5) Setelah langkah-langkah di atas mampu dilakukan dengan baik selanjutnya perkenalkan si anak dengan kolam yang sedikit lebih dalam (bawa si anak ke air yang tingginya sampai di dada atau leher). 6) Pelatih mengajak si anak untuk membasuh mukanya sendiri. Selalu berikan kata-kata yang merayu dan memotivasi. 7) Pelatih mengajak si anak untuk memasukkan seikit demi sedikit kepala bagian belakang si anak ke dalam air dan diamkan beberapa saat ( berguna sebagai relaksasi). 8) Pelatih mengajak si anak untuk masuk ke dalam air. Beri aba aba yang mudah dimengerti agar anak tidak tersedak saat di dalam air. 9) Pelatih mengajarkan cara kaki bergerak di air. 10) Setelah langkah nomor 8 dan 9 mampu dilakukan dengan baik, maka selanjutnya pelatih mengajak orang tua untuk menangkap si anak dengan cara si anak dipegang oleh pelatih dengan posisi berhadapan dengan orang tua, kemudian beri jarak sekitar kurang lebih 2 meter antara pelatih dan orang tua. 11) Perbanyak anak bermain dengan air agar dia terbiasa dan melupakan ketakutannya. Lakukan langkahlangkah di atas sebagai rutinitas guna 
menghilangkan phobia air.

Instrumen penelitian dalam mengembangkan metode CST untuk mengatasi phobia air pada anak usia dini menggunakan instrumen angket dan dokumentasi pada tahap validasi rancangan produk satu orang ahli renang sedangkan pada pada tahap validasi produk, uji coba satu dan uji coba dua menggunakan instrumen angket yang sudah tervalidasi untuk mengukur kualitas kelayakan metode CST dalam mengatasi phobia air pada anak usia dini.

Analisis data yang digunakan dalam penelitian ini menggunakan analisis subjek tunggal untuk mengolah hasil ujicoba kelompok I dan kelompok II dimana hasilnya berupa presen (100\%) (Sunanto J, dkk: 2005,p:16) dan grafik.

\section{Hasil}

Dalam penelitian ini menggunakan analisis subjek tunggal, dimana data yang ada di rubah menjadi persen $(100 \%)$ yang diambil dari data angket phobia sebelum dan sesedah penelitian dilakukan kemudian dituangkan dalam desain grafik untuk mengetahui tingkat phobia subjek setelah dilakukan uji coba.

a. Subjek di Titos Swimming Grup

Tabel 1. Data Angket Phobia Titos

\begin{tabular}{|c|c|c|c|c|}
\hline \multirow{2}{*}{$\begin{array}{c}\text { Jumlah Data } \\
\text { Keseluruhan }\end{array}$} & \multicolumn{2}{|c|}{$\begin{array}{c}\text { Sebelum Uji } \\
\text { Coba }\end{array}$} & \multicolumn{2}{c|}{$\begin{array}{c}\text { Sesudah Uji } \\
\text { Coba }\end{array}$} \\
\cline { 2 - 5 } & $\begin{array}{c}\text { Jumlah } \\
\text { Data } \\
\text { (point) }\end{array}$ & & $\begin{array}{c}\text { Jumlah } \\
\text { Data } \\
\text { (point) }\end{array}$ & $\%$ \\
\hline 120 & 65 & 54,1 & 18 & 15 \\
\hline
\end{tabular}

Jumlah yang di dapat dari angket phobia air sebelum uji coba sebanyak 65 point dengan presentasi $54,1 \%$ dan sesudah uji coba sebanyak 18 point dengan presentasi 15\%. Dari data tersebut bisa di ketahui bahwa terdapat penurunan sebesar 47 point dengan selisih presentasi 39,1\%.

Hal ini membuktikan bahwa subjek yang memiliki phobia air bisa terselesaikan melalui pemberian metode uji coba CST dengan mengikuti tahap selanjutnya dan dilakukan sesuai dengan modul dalam CST dengan beberapa tambahan seperti memasukkan kepala ke dalam air dan mengambil mainan di dalam kolam yang akhirnya dapat menyembuhkan ketakutan atau phobia anak terhadap air.

b. Subjek kedua di TK Aisyiyah Bebekan Sepanjang

Tabel 2. Data Angket Phobia TK Aisyiyah

\begin{tabular}{|c|c|c|c|c|}
\hline \multirow{2}{*}{$\begin{array}{c}\text { Jumlah Data } \\
\text { Keseluruhan }\end{array}$} & \multicolumn{2}{|c|}{$\begin{array}{c}\text { Sebelum Uji } \\
\text { Coba }\end{array}$} & \multicolumn{2}{c|}{$\begin{array}{c}\text { Sesudah Uji } \\
\text { Coba }\end{array}$} \\
\cline { 2 - 5 } & $\begin{array}{c}\text { Jumlah } \\
\text { Data } \\
\text { (point) }\end{array}$ & & $\begin{array}{c}\text { Jumlah } \\
\text { Data } \\
\text { (point) }\end{array}$ & \\
\hline 120 & 66 & 55 & 15 & 12,5 \\
\hline
\end{tabular}

Sedangkan pada subjek II jumlah yang di dapat dari angket phobia air sebelum uji coba sebanyak 66 point dengan presentasi 55\% dan sesudah uji coba sebanyak 15 point dengan presentasi $12,5 \%$. Dari data tersebut bisa di ketahui bahwa terdapat penurunan sebesar 51 point dengan selisih presentasi 42,5\%. Pada subjek ini dilakukan sesuai dengan modul yang sudah direvisi sebelumnya dan masukan final dari subjek ini adalah perlu adanya paksaan yang dikatakan wajar serta memberikan reward atau hadiah setiap anak berhasil melakukan tugas yang diberikan oleh pelatih, hal ini bertujuan untuk memberikan semangat kepada anak agar berani untuk memasuki kolam renang.

Gambar 1. Grafik Perubahan Sebelum Dan Setelah Uji Coba Kedua Kelompok

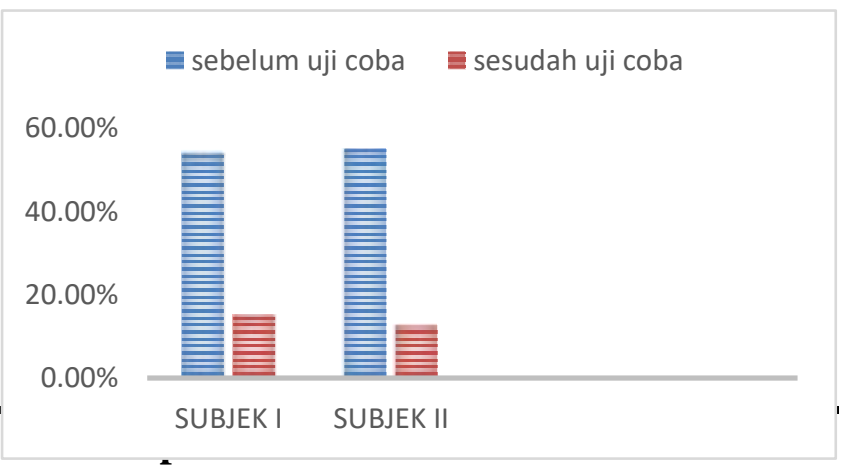

Communicative Swimming Training (CST) 
memiliki 11 tahapan atau langkah-langkah yang bisa diikuti untuk mengatasi phobia air pada anak usia dini. Keefektifan metode ini dibuktikan dengan adanya penurunan angka presentase jumlah data pada subjek I terjadi penurunan sebesar 39\% dan pada subjek II terjadi penurunan sebesar $42 \%$ yang diambil dari selisih data sebelum dan sesudah uji coba. Hal ini membuktikan bahwa metode ini bisa mengurangi phobia air yang dialami oleh anak usia dini dan metode ini lebih efektif dilakukan pada usia dini karena emosional pada anak usia dini masih bisa diatur daripada usia pra remaja atau sekitar 9 tahun ke atas.

Untuk peneliti selanjutnya agar diperhatikan dalam mengembangkan penelitian ini contohnya seperti kondisi kesehatan anak yang mengalami phobia air, kondisi air kolam yang akan digunakan untuk treadment serta modifikasi-modifikasi perlakuan guna mempermudah menangani anak yang phobia air maupun untuk jenis-jenis phobia lainnya dan memperhatikan setiap item yang akan dikembangkan, atau juga bisa mengembangkan penelitian ini dengan mencari sisi-sisi lingkungan serta penyebabnya dari anak-anak yang mengalami phobia air.

\section{DAFTAR PUSTAKA}

Aleksandrovic, dkk. (2010). Effects Of Adapted Swimming Program Onto Orientation In Water Of Childrend Eith Neuromuscular Impairments. Proceedings of The 5th Internasional Congress.

Farokie, dkk. (2016). Pengaruh Metode Latihan Dry Land Sirkuit Dan Latihan Renang Sprint Terhadap Kemampuan Kecepatan Renang Gaya Crawl 50 Meter. Universitas Negeri Malang. Jurnal Pendidikan Jasmani. Vol. 26. No.1.

Jorgic, dkk. (2011). Importance Of Maximal Oxygen Consumption During Swimmming. Physical Education And
Sport. Vol. 9. No. 2, Pp 183-191.

Sugiyono. (2015). Metode Penelitian Pendidikan. Bandung: Alfabeta.

Sunanto J, dkk. (2005). Pengantar Penelitian Dengan Subjek Tunggal. CRICED University of tsukuba. 